\title{
Laboratory testing of low temperature asphalt concrete produced in foamed bitumen technology with fiber reinforcement
}

\author{
A. CHOMICZ-KOWALSKA* \\ Civil Engineering and Architecture, Kielce University of Technology, 7 Tysiąclecia Państwa Polskiego Ave., 25-314 Kielce, Poland
}

\begin{abstract}
The paper presents the design process and test results of warm mix asphalt concrete produced with modified foamed bitumen and recycled synthetic fiber reinforcement. Recycling and low-temperature asphalt production techniques are now seen as the possibilities to increase the sustainability and energy effectiveness of road construction. Although low processing temperatures permit increased use of reclaimed and recycled materials in new asphalt mixes, they sometimes result in impaired service performance. The aim of this article was to present a possibility of producing a better performing asphalt concrete (in comparison to a control hot-mix) at lower temperatures. For this purpose two road paving bitumens modified with a surface active agent and a Fischer-Tropsch wax thoroughly tested for their basic, rheological characteristics and foaming performance. Selected binders were used for producing two control mixes (hot-mix and foamed warm mix with 35/50 bitumen) as well as the experimental mix with the modified 50/70 bitumen and an addition of synthetic fiber material from recycling of automotive tires. Basic properties of the mixes were tested (air void content, moisture susceptibility with one freeze-thaw cycle, wheel tracking) along with stiffness moduli and fatigue resistance. It was concluded that the control foamed warm-mix performed significantly worse than the hot-mix, while the experimental warm-mix with modified bitumen and fiber additive exhibited increased performance and resistance to fatigue and moisture.
\end{abstract}

Key words: warm mix asphalt (WMA), foamed bitumen, surfactant, fiber, Fischer-Tropsch wax.

\section{Introduction}

The increasing demands for more sustainable, more durable and cleaner infrastructure drives the development and implementation of new technical solutions in road construction. The classic approach to achieve those goals is to recycle road paving materials in construction of new roads. Recent developments aim at maximizing the recycling ratio while retaining the quality of newly produced pavements [1-4]. Much effort is put into refining and understanding different processes for producing warm-mix and half-warm asphalt mixes [5-8], cold deep recycled mixes [9], as well investigating novel additives opening new possibilities [10]. With the rise of new classes of paving materials, new binders for improving subgrade are developed [11], pavement mechanics and requirements are constantly being better understood and formulated $[12,13]$. In the recent years, much work has been done to properly describe the non-elastic behavior of bituminous materials, with special considerations to their fatigue characteristics $[14,15]$. As many of these new techniques are already well established, the focus of the researchers must be shifted towards assuring longevity and reliability of these new solutions. To maximize the benefits of recycling and aforementioned new techniques in road construction, ideas of continuously inspecting current condition of roads need to be adopted using modern management and

*e-mail: akowalska@tu.kielce.pl

Manuscript submitted 2017-07-18, revised 2017-11-09, initially accepted for publication 2017-11-15, published in December 2017. maintenance strategies [16], in turn enabling a dynamic balance between performance, reliability and cost [17].

Utilization of foamed bitumen with conjunction with certain additives may permit production of bituminous mixes and paving of asphalt at temperatures out of reach of the classic warm mix asphalt techniques. Obtaining adequate compaction and service performance in these techniques requires usually the combined use of surface active agents and low viscosity wax additives. Low temperature asphalt mixes produced and placed at considerably lower temperatures compared to conventional hot mix asphalt require particular attention and adequate compaction because climatic factors (water and frost) as well as traffic loads can have a larger impact on their durability and service life. The extent of this problem increases when acidic aggregates are used and coating them fully and permanently with asphalt binder may be difficult. Premature failure in asphalt containing hydrophilic (acidic) aggregates due to water and frost damage can be prevented by using additives strengthening the adhesion between the bitumen and the aggregates.

The use of typical adhesion promoters either alters the interfacial conditions at the aggregate-bitumen phase boundaries or improves the adhesive bond between the two. The first group of modifiers improves the wetting of aggregates by the binder so that it is favored over wetting with water, while the latter increase natural cohesive forces arising from the interaction of electrostatic charges in the bitumen particles and on the aggregate surface. Both these actions lead to the improvement of bitumen adhesion to aggregates, thus increasing the resistance of asphalt mixes to water damage. This is particularly 
important when the mixture is manufactured at lower temperatures in foamed bitumen technology with the foamed binder containing water. Additionally, in this technology aggregates may contain minor amounts of moisture. In Poland, the most commonly applied additives for aggregate-bitumen adhesion improvement include liquid compounds from the fatty amine group and their derivatives. Two distinct methods are used to introduce additives to the mixture: the hot method - the additive of high thermostability is mixed together with binder - in this method the binder with the additive is stored at elevated temperatures ( $\max .190^{\circ} \mathrm{C}$ ), even for a few days. In the other method the liquid additive is injected into the hot bitumen line by a pump just before the mixing chamber, in which case the bitumen-additive mixing time at high temperatures is relatively short. In the laboratory trials, the additive was added to the bitumen shortly before the foaming process.

To secure the designed service life of a flexible pavement it is necessary to ensure a sufficient fatigue resistance and durability of the individual asphalt layers. Newly designed, sustainable asphalt pavements must be also resistant to the development of permanent deformation (rutting) and to water and frost damage. In addition to additives and modifiers in bituminous binders, fibrous materials can be used to ensure stability of the mix and for strengthening its internal structure and improving its service performance. Adequately composed combination of the aforementioned solutions may be used to produce asphalt mixes with better parameters compared to the conventional, energy-intensive hot mix asphalt.

\section{Experimental program}

This study concentrated on the design of asphalt mix with improved physical, mechanical and service properties, using two modifiers: a Fischer-Tropsch $(F T)$ synthetic wax and a surface active agent. To further improve the performance of the ecological low temperature foam bitumen mix, a fibrous material was added during its manufacture. By considerably changing the properties of the binder, the synthetic wax would improve workability and compactibility of the mix and increase its resistance to rutting. Addition of the surfactant would have an effect on increased compactibility of asphalt concrete and on its decreased susceptibility to moisture damage. Synthetic fibers, acting as reinforcement, would strengthen the asphalt concrete mix structure, improving rutting resistance and increasing its fatigue performance. The mineral mix was partially composed of quartzite (hard, acidic aggregates) as this resulted in a mineral mix that was more durable and better suited for medium and heavy traffic loads than one based purely limestone or dolomite for compliance with national requirements.

Laboratory testing was conducted on the AC 16 binding course asphalt concrete mix for medium traffic loads $\left(0.5 \div 7.3 \times 10^{6}\right.$ $\left.\mathrm{ESAL}_{100 \mathrm{kN}}\right)$ in accordance with the requirements set out in PN-EN-13108-1:2008 and in Technical Requirements for road paving asphalt mixes in Poland TG-2 2010 [18].

Comparative tests for selected properties of the $\mathrm{AC}$ mixes were performed on three mixes:
- Mix-A - the reference hot mix asphalt concrete with 35/50 bitumen;

- Mix-B - low temperature with 35/50 foamed bitumen $\operatorname{mix}$

- Mix-C - 50/70 foamed bitumen mix modified with $2.5 \%$ FT synthetic wax with addition of $0.6 \%$ surfactant by bitumen mass (surf.) and synthetic fibers (fib.) in the amount of $0.2 \%$ by mass of the mix.

\section{Study of bituminous binders to be used in experimental HMA and WMA with foamed bitumen}

3.1. Materials. The first stage of the study of bituminous binders used petroleum grade bitumen 35/50 and 50/70, and the binders produced by adding the FT wax and/or the surfactant to the bitumen.

3.1.1. Bituminous binders. A variety of road bitumen types are used to produce asphalt mixtures depending on their purpose. The basic function of a bituminous binder is to permanently coat and bind aggregates in the mixture, forming a monolithic composite with adequate mechanical properties, stable throughout the life cycle of the pavement. Securing this goal depends on the chemical composition and rheological characteristics of the bitumen used [19-21]. Neat 35/50 and 50/70 paving grade bitumens were used as base binders in the laboratory tests, as they are recommended for binder course AC mixes under medium traffic loads $\left(0.5 \div 7.3 \times 10^{6} \mathrm{ESAL}_{100 \mathrm{kN}}\right)$ by the Technical Requirements TG-2 2010 [18]. To select a proper binder for the low temperature asphalt mixture with improved performance, FT wax, fatty amine-based surfactant and a blend of both modifiers were added to the two bitumens. The relevance of their use is explained in the further part of this article.

3.1.2. Fischer Tropsch synthetic wax. Chemically, it is a longchain aliphatic hydrocarbon wax produced in the Fischer-Tropsch process. The wax melts completely at ca. $115^{\circ} \mathrm{C}$ and while cooling, recrystallization begins at ca. $105^{\circ} \mathrm{C}$ and is completed at $65^{\circ} \mathrm{C}$ [22]. The FT wax contains no metals or heteroatoms such as chlorine, sulphur, nitrogen and oxygen.

Modification of the bitumen with the FT wax lowers the viscosity of the binder at processing temperatures, allowing mixing and compaction at temperatures substantially lower than that of hot mix asphalt mixing. Advantages include reduced emissions, saved energy, improved labor conditions and shortened production cycle. At temperatures below the FT wax solidification point (after compaciton), the FT wax lattice structure in the bitumen makes the binder stiffer, thus increasing the resistance of the mixture to permanent deformation (rutting) [23-25].

The synthetic wax was added at $2.5 \%$ to modify base bitumens subjected to further modification with surface active agent and water foaming. The content of the FT wax was established on the basis of the authors' original research results and on the findings reported by other researchers [24-26]. 
3.1.3. Surface active agent. Hydrophilic aggregates (quartzite $0 / 2 \mathrm{~mm}$ and $16 / 22 \mathrm{~mm}$ ), which are acidic, were used in the mixes. The choice of these aggregates was governed by their frequent use in real pavements under medium and heavy traffic loads. The use of hydrophilic aggregates should make any increase in the sensitivity to water and frost damage due to the low temperature production technique more pronounced, compared to a purely limestone or dolomite mix. Therefore, in order to improve the binder's adhesion to aggregates and mix's resistance to water, the $0.6 \%$ of liquid fatty-amine-based adhesion agent was incorporated into hot binder during the laboratory tests. Table 1 compiles the properties of the adhesion agent used.

Table 1

Properties of the surface active agent [27]

\begin{tabular}{|l|c|c|}
\hline Property & Unit & Value \\
\hline Density at $20^{\circ} \mathrm{C}$ & $\mathrm{kg} / \mathrm{m}^{3}$ & 980 \\
\hline Amine value & $\mathrm{mg} \mathrm{HCl} / \mathrm{g}$ & $159-185$ \\
\hline Acid value & $\mathrm{mg} \mathrm{KOH} / \mathrm{g}$ & $<10$ \\
\hline Solidification temperature & ${ }^{\circ} \mathrm{C}$ & $<0$ \\
\hline Ignition temperature & ${ }^{\circ} \mathrm{C}$ & $>218$ \\
\hline
\end{tabular}

\subsection{Methodology.}

3.2.1. Testing of bituminous binders before foaming. Basic parameters for the bituminous binders, i.e., consistency, thermal sensitivity and resistance to low temperatures were determined by the following laboratory tests:

- penetration at $25^{\circ} \mathrm{C}$ (Pen25) to PN-EN 1426:2015-08 (9 replicates),

- softening point/ring and ball method $\left(\mathrm{T}_{\mathrm{R} \& \mathrm{~B}}\right)$ to PN-EN 1427:2015-08 (6 replicates),

- Fraass breaking point ( $\left.\mathrm{T}_{\text {Fraass }}\right)$ to PN-EN 12593:2015-08 (6 replicates).

The following parameters were established from the tests results:

- penetration index (PI) to PN-EN 12591:2010,

- plasticity range (PR) to PN-EN 14023:2011.

The binders used in the asphalt mixtures were also tested for basic rheological characteristics in a wide range of temperatures and different loading modes:

- dynamic viscosity in a $60^{\circ} \mathrm{C} \div 160^{\circ} \mathrm{C}$ temperature range, using a rotational viscometer (4 replicates),

- $\mathrm{G}^{*} / \sin \delta$ at $40^{\circ} \mathrm{C}, 50^{\circ} \mathrm{C}, 60^{\circ} \mathrm{C}, 70^{\circ} \mathrm{C}$ and $80^{\circ} \mathrm{C}$, using a direct shear rheometer (DSR) at a loading frequency of $1.59 \mathrm{~Hz}$ (6 replicates),

- complex shear modulus master curves established based on DSR testing at multiple temperatures $\left(40^{\circ} \mathrm{C}, 50^{\circ} \mathrm{C}\right.$, $\left.60^{\circ} \mathrm{C}, 70^{\circ} \mathrm{C}, 80^{\circ} \mathrm{C}\right)$ and frequencies $(0.1 \mathrm{~Hz} \div 10 \mathrm{~Hz})$ (6 replicates).

The rotational viscometer testing was carried out in accordance with the EN 13702-2:2010 standard while the direct shear rheometer tests were performed in accordance with AASHTO T315. Test samples were prepared to PN-EN 12594:2014-12.
3.2.2. Testing of foamed bitumen binders. Foamed bitumens were produced from base binders (35/50 and 50/70) and from base binders modified with a surface active agent, the FT modifier or a blend of both materials. For the resulting 8 binders the maximum expansion ratio (ERm) and half-life (HL) were measured under the following foaming conditions: bitumen temperature (before foaming): $155^{\circ} \mathrm{C}$, foaming water temperature: ca. $20^{\circ} \mathrm{C}$, water flow: $100 \mathrm{~g} / \mathrm{s}$, air pressure: $500 \mathrm{kPa}$, water pressure: $550 \mathrm{kPa}$. The bitumen temperature prior to foaming was chosen so that similar expansion ratios of the two used base bitumen would be achieved, providing a baseline for comparisons.

Bitumen foam parameters were measured at different foaming water contents (FWC): $1.5 \%, 2.5 \%$ and 3.5\%, four times for each item of the experimental plan.

The modifiers were added to the bitumens $35 / 50$ and 50/70 directly before foaming (i.e., to the heated tank of the foamed bitumen plant Wirtgen WLB 10S ensuring adequate homogenization of the blend.

\subsection{Test results and analysis.}

3.3.1. Paving grade bitumen - results and analysis. The tests for the basic properties of bitumen 35/50 and 50/70 with and without the FT modifier and/or surfactant comprised penetration at $25^{\circ} \mathrm{C}$ (Pen25), softening point $\left(\mathrm{T}_{\mathrm{R} \& \mathrm{~B}}\right)$ and the determination of Fraass breaking point ( $\left.\mathrm{T}_{\text {Fraass }}\right)$.

The first two quantities were used to calculate the penetration index (PI), which is a conventional measure of bitumen temperature sensitivity and which may be useful for the evaluation of bitumen stiffness changes due to temperature. The softening point and the Fraass breaking point results were used to establish the plasticity range, $P R$, i.e., the temperature range within which bituminous binders are classically assumed to retain viscoelastic properties. The value in this range should be as high as possible with the binder having the lowest possible breaking point and the highest possible softening point. Table 2 summarizes the test results.

Table 2

Properties of bituminous binders

\begin{tabular}{|l|c|c|c|c|c|}
\hline Binder & $\begin{array}{c}\text { Pen25 } \\
{[\mathbf{0 . 1} \mathbf{~ m m}]}\end{array}$ & $\begin{array}{c}\mathbf{T}_{\mathbf{R \& B}} \\
{\left[{ }^{\circ} \mathbf{C}\right]}\end{array}$ & $\begin{array}{c}\mathbf{T}_{\text {Fraass }} \\
{\left[{ }^{\circ} \mathbf{C}\right]}\end{array}$ & $\begin{array}{c}\text { PI } \\
{[-]}\end{array}$ & $\begin{array}{c}\text { PR } \\
{\left[{ }^{\circ} \mathbf{C}\right]}\end{array}$ \\
\hline $35 / 50$ & 36.4 & 54.4 & -13.7 & -0.86 & 68.1 \\
\hline $35 / 50+0.6 \%$ surf. & 34.9 & 54.3 & -13.3 & -0.98 & 67.6 \\
\hline $35 / 50+2.5 \% \mathrm{FT}$ & 23.3 & 78.9 & -11.0 & 2.37 & 89.9 \\
\hline $35 / 50+2.5 \% \mathrm{FT}+0.6$ surf. & 23.2 & 78.9 & -12.0 & 2.36 & 90.9 \\
\hline $50 / 70$ & 59.9 & 48.5 & -16.3 & -1.18 & 64.8 \\
\hline $50 / 70+0.6 \%$ surf. & 53.5 & 48.9 & -16.3 & -1.33 & 65.2 \\
\hline $50 / 70+2.5 \% \mathrm{FT}$ & 34.6 & 75.1 & -12.0 & 2.70 & 87.1 \\
\hline $50 / 70+2.5 \% \mathrm{FT}+0.6$ surf. & 37.0 & 75.1 & -13.0 & 2.87 & 88.1 \\
\hline
\end{tabular}

Analysis of the test results indicates the influence of FT wax modification in both types of binders and a negligible effect arising from the presence of the surface active agent. 
Maximum change in penetration of the modified binders in the first group $(35 / 50)$ was $13.2 \cdot 0.1 \mathrm{~mm}$, while a larger change $(22.9 \cdot 0.1 \mathrm{~mm})$ was observed in softer binders $(50 / 70)$. The $2.5 \%$ addition of FT wax resulted in obtaining significantly harder binders. The $35 / 50$ binder $(\operatorname{Pen} 25=36.4 \cdot 0,1 \mathrm{~mm})$ transgressed into the $20 / 30$ penetration range $(\operatorname{Pen} 25=23.2 \cdot 0,1 \mathrm{~mm}$ ), while the original $50 / 70$ binder $(\operatorname{Pen} 25=59.9 \cdot 0.1 \mathrm{~mm})$ transgressed into the $35 / 50$ penetration range $($ Pen $25=37.0 \cdot 0.1 \mathrm{~mm})$. The softening temperature increased noticeably after adding FT wax: by $24.5^{\circ} \mathrm{C}$ in the first group and by $26.2^{\circ} \mathrm{C}$ in the second group. Both $35 / 50$ and $50 / 70$ bitumens modified solely with FT wax as well as modified simultaneously with FT wax and the surface active agent considerably exceeded (by about $21^{\circ} \mathrm{C}$ ) the softening point upper limit for their original specifications (i.e. $58^{\circ} \mathrm{C}$ as per PN-EN 12591:2010 for bitumen $35 / 50$ and $54^{\circ} \mathrm{C}$ for bitumen 50/70). A minor increase in breaking temperature was observed in 35/50 and 50/70 bitumen modified with FT wax (about $2^{\circ} \mathrm{C}$ and $4^{\circ} \mathrm{C}$, respectively). A considerable increase in softening temperature of FT wax modified binders will increase the resistance of asphalt concrete to permanent deformation. Results show that calculated PI values increased for bitumen with FT wax (and with the blend of FT wax and surfactant ) and were classified as gel-type bitumen [28], while a decrease of PI was observed in bitumen containing $0.6 \%$ surfactant. The addition of $2.5 \%$ modifier in the $35 / 50$ bitumen limits the thermal sensitivity of the binder but its increased stiffness may lead to increased low temperature brittleness. The $0.6 \%$ addition of surfactant reduced temperature plasticity ranges (PR) only slightly, by about $0.5 \%$ in relation to the neat bitumen. The presence of FT wax increased PR ranges by more than $22^{\circ} \mathrm{C}$, which translates into increased temperature ranges within which binders retain viscoelastic properties.
The results show that for the low temperature asphalt mix with acidic aggregates to be resistant to permanent deformation and water/frost damage, the use of foamed bitumen 50/70 containing both the wax and the surfactant will be most advantageous. Modification of bitumen 35/50 disqualifies it from being used in the mix due to excessive hardness (penetration in $20 / 30$ range). The Polish guidelines [18] do not allow bitumen with that low penetration values in the construction of binder courses.

Figure 1 shows the results of dynamic viscosity testing of selected paving grade bitumen: $35 / 50,50 / 70$ and the 50/70 bitumen with $2.5 \%$ FT wax content and $0.6 \%$ surfactant content. Tests were conducted temperature range between $60^{\circ} \mathrm{C}$ and $160^{\circ} \mathrm{C}$

The results of dynamic viscosity testing allow estimation of the required production and paving temperatures of hot mix asphalt on the basis of the conventional viscosity limits: $0.2 \mathrm{~Pa} \cdot \mathrm{s}$ for satisfactory bitumen coating, and $2 \mathrm{~Pa} \cdot \mathrm{s}$ to $20 \mathrm{~Pa} \cdot \mathrm{s}$ for optimal compaction. There is a significant, positive effect of the 50/70 bitumen modification throughout the production and paving temperatures. The decrease in viscosity of the modified 50/70 bitumen at production temperatures should have a positive impact on the process of aggregate coating and mixing. At intermediate production temperatures, the minor but observable decrease in viscosity will result in improved workability, alternatively compaction can be extended into lower temperatures compared with the $35 / 50$ or even $50 / 70$ base binders. The presented low-temperature viscosity characteristics of the binders $\left(<90^{\circ} \mathrm{C}\right)$ show that the modified $50 / 70$ binder responds similarly to the harder $35 / 50$ base bitumen due to the addition of FT wax, presumably resulting in improved performance at high service temperatures. Based on dynamic viscosity test results, one can infer that the observed response of the modified 50/70 bitumen

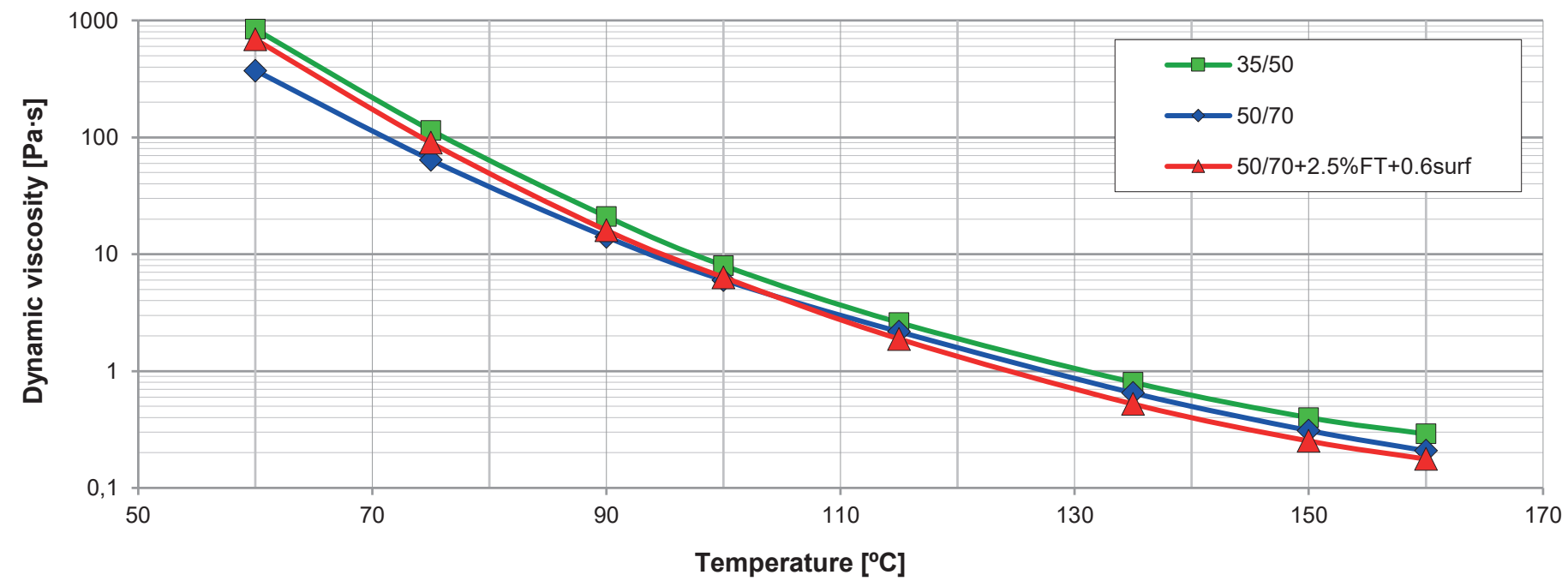

\begin{tabular}{|c|c|c|c|c|c|c|c|c|}
\hline \multirow{2}{*}{ Type of bitumen binder } & \multicolumn{8}{|c|}{ Dynamic viscosity std. dev. } \\
\hline & $60^{\circ} \mathrm{C}$ & $75^{\circ} \mathrm{C}$ & $90^{\circ} \mathrm{C}$ & $100^{\circ} \mathrm{C}$ & $115^{\circ} \mathrm{C}$ & $135^{\circ} \mathrm{C}$ & $150^{\circ} \mathrm{C}$ & $160^{\circ} \mathrm{C}$ \\
\hline $35 / 50$ & 27.2386 & 4.0365 & 0.8001 & 0.2792 & 0.1001 & 0.0269 & 0.0156 & 0.0106 \\
\hline $50 / 70$ & 14.2821 & 2.0649 & 0.4967 & 0.1872 & 0.0736 & 0.0217 & 0.0113 & 0.0076 \\
\hline $50 / 70+2.5 \% \mathrm{FT}+0.6 \mathrm{surf}$ & 37.1371 & 5.3100 & 0.9984 & 0.4451 & 0.1073 & 0.0313 & 0.0188 & 0.0125 \\
\hline
\end{tabular}

Fig. 1. The results of dynamic viscosity tests of the selected binders 


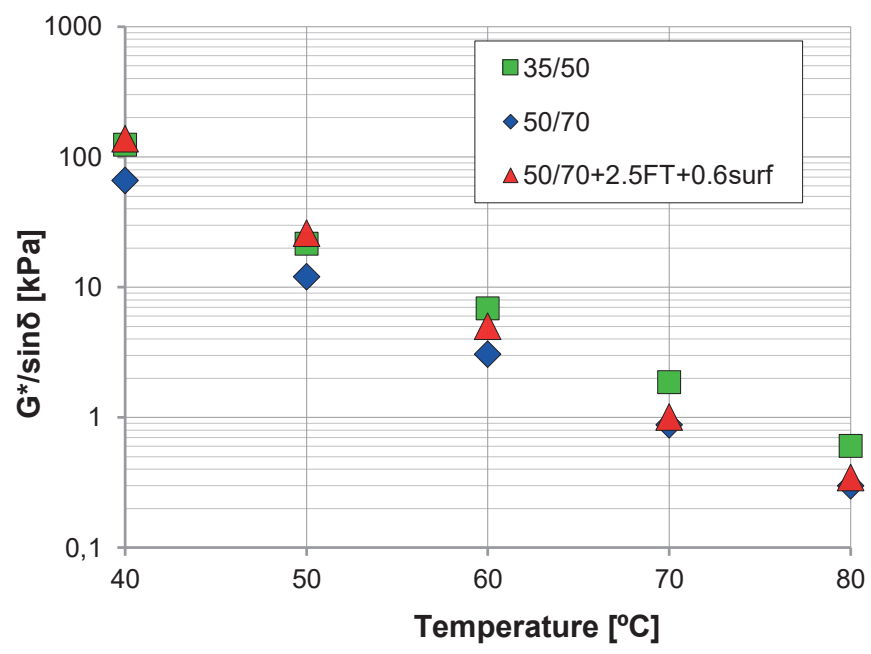

\begin{tabular}{lccccc}
\hline \multirow{2}{*}{ Type of bitumen binder } & \multicolumn{5}{c}{$\mathrm{G}^{*} / \mathrm{sin} \delta$ std. dev. } \\
\cline { 2 - 6 } & $40^{\circ} \mathrm{C}$ & $50^{\circ} \mathrm{C}$ & $60^{\circ} \mathrm{C}$ & $70^{\circ} \mathrm{C}$ & $80^{\circ} \mathrm{C}$ \\
\hline $35 / 50$ & 4.8193 & 0.7312 & 0.2328 & 0.0561 & 0.0212 \\
$50 / 70$ & 2.4233 & 0.4603 & 0.9824 & 0.0293 & 0.0108 \\
$50 / 70+2.5 \% \mathrm{FT}+0.6$ surf & 7.8147 & 1.4457 & 0.2700 & 0.0557 & 0.0188 \\
\hline
\end{tabular}

Fig 2. Values of $\mathrm{G}^{*} / \sin \delta$ in selected binders

was mainly caused by the addition of FT wax, while the influence of the surfactant additive on the dynamic viscosity of the bitumen was negligible (results are not shown for legibility).

Similarly, as for the basic tests, all of the produced binders were tested for $\mathrm{G}^{*} / \mathrm{sin} \delta$ at different temperatures using a dynamic shear rheometer. Table 3 and Fig. 2 summarize the values of $\mathrm{G}^{*} / \sin \delta$ measured at $40^{\circ} \mathrm{C}, 50^{\circ} \mathrm{C}, 60^{\circ} \mathrm{C}, 70^{\circ} \mathrm{C}$ and $80^{\circ} \mathrm{C}$. The influence of the FT wax modification on the bitumen is similar to that observed during the dynamic viscosity testing. As can be seen in Fig. 2, under oscillatory loading in the linear viscoelastic region, the performance characteristic of the $50 / 70+2.5 \mathrm{FT}+0.6$ surf. binder transitions from the curve describing neat 50/70 bitumen to the one characterizing $35 / 50$
Table 3

Values of $\mathrm{G}^{*} / \sin \delta$ in the base and modified binders measured in the temperature range $40^{\circ} \mathrm{C}$ to $80^{\circ} \mathrm{C}$

\begin{tabular}{|l|r|c|c|c|c|}
\hline \multirow{2}{*}{ Binder } & \multicolumn{5}{|c|}{$\mathbf{G}^{*} / \mathbf{s i n} \boldsymbol{\delta}(\mathbf{k P a})$} \\
\cline { 2 - 6 } & $\mathbf{4 0}^{\circ} \mathbf{C}$ & $\mathbf{5 0}^{\circ} \mathbf{C}$ & $\mathbf{6 0}^{\circ} \mathbf{C}$ & $\mathbf{7 0}^{\circ} \mathbf{C}$ & $\mathbf{8 0}^{\circ} \mathbf{C}$ \\
\hline $35 / 50$ & 124.53 & 21.70 & 6.87 & 1.86 & 0.61 \\
\hline $35 / 50+0.6$ surf. & 119.32 & 23.75 & 6.17 & 1.70 & 0.54 \\
\hline $35 / 50+2.5 \mathrm{FT}$ & 221.70 & 46.48 & 9.87 & 2.37 & 0.64 \\
\hline $35 / 50+2.5 \mathrm{FT}+0.6$ surf. & 214.54 & 46.14 & 9.50 & 2.26 & 0.64 \\
\hline $50 / 70$ & 66.03 & 12.02 & 3.07 & 0.88 & 0.30 \\
\hline $50 / 70+0.6$ surf. & 58.13 & 11.92 & 2.93 & 0.82 & 0.28 \\
\hline $50 / 70+2.5 \mathrm{FT}$ & 142.32 & 26.72 & 5.17 & 1.12 & 0.35 \\
\hline $50 / 70+2.5 \mathrm{FT}+0.6$ surf. & 138.07 & 26.05 & 5.02 & 1.01 & 0.35 \\
\hline
\end{tabular}

binder between $50^{\circ} \mathrm{C}$ and $80^{\circ} \mathrm{C}$. Unlike in dynamic viscosity testing (where the modified 50/70 bitumen did not achieve the $35 / 50$ binder performance), here the stiffness of the modified $50 / 70$ bitumen exceeds the stiffness of the $35 / 50$ bitumen at ca. $50^{\circ} \mathrm{C}$ and further diverges with the temperature reduction. This observation can be explained by the nature of dynamic viscosity testing, in which the internal structure of the binder, together with the FT-wax lattice is significantly disrupted. Hence, the stiffening effect of the FT-wax in these tests is far less pronounced than that in oscillatory loading test. As for the addition of $0.6 \%$ of the surfactant, the effects observed in the oscillatory testing are apparent, however not very significant. The addition of the surfactant resulted in a slight decrease in binder stiffness at temperatures up to $70^{\circ} \mathrm{C}$. No obvious interaction between the FT-wax and the surfactant was observed.

Figure 3 shows complex shear modulus master curves of three selected binders $(35 / 50,50 / 70,50 / 70+2.5 \mathrm{FT}+0.6$ surf. $)$ calculated on the basis of oscillatory tests conducted for a wide range of temperatures and loading frequencies.

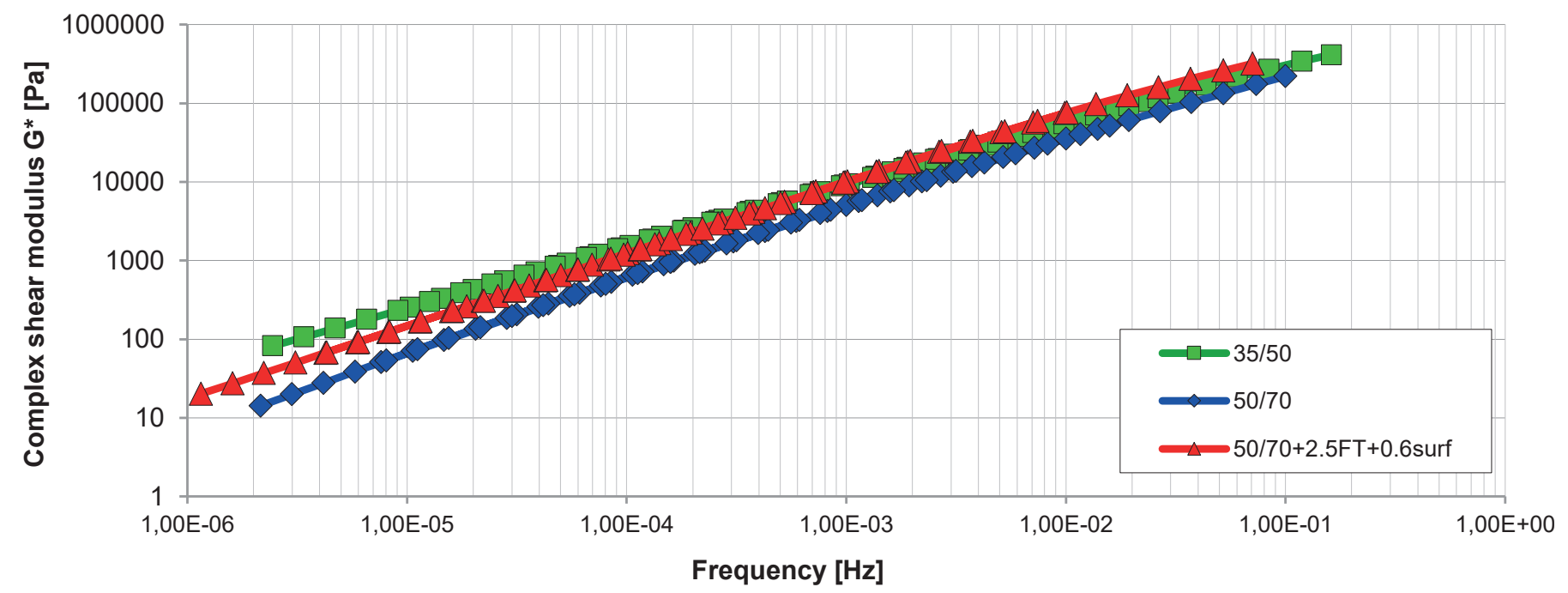

Fig. 3. The results of direct shear rheometer testing of selected binders (complex shear moduli vs. frequency) 
The results support the previous findings regarding a significant positive influence of the FT wax modification on the 50/70 binder and are consistent with the results of penetration, softening point and dynamic viscosity tests as well as with $\mathrm{G}^{*} / \sin \delta$ results. The $50 / 70+2.5 \mathrm{FT}+0.6$ surf. binder exhibits higher values of complex stiffness modulus in the whole range of frequencies and shows a noticeable improvement in performance compared to the $35 / 50$ binder in the high frequency region (low temperature equivalent). In the intermediate region, the 50/70 modified binder and 35/50 paving bitumen perform similarly.

These observations show that the $50 / 70+2.5 \mathrm{FT}+0.6$ surf. binder can be used instead of the $35 / 50$ paving grade bitumen to provide superior workability of the aggregate-bitumen mixture.

3.3.2. Foamed bitumen- results and analysis. The base bituminous binders $(35 / 50$ and 50/70) along with the blends described in $[25,26,29]$ were tested for their foaming characteristics. As shown in [25, 26, 29], binder modification may lead to significant changes in foaming performance, sometimes leading to inadequate foaming.

Figure 4 shows foaming characteristics (expansion ratio - ERm and half-life - HL) of the tested base 35/50 and modified binders with different amounts of foaming water used. Figure 5 summarizes the bitumen foaming characteristics of the 50/70 base and modified bituminous binders. To adequately assess the bitumen foam properties, the parameters were measured four times for each of the foaming water contents of $1.5 \%, 2.5 \%$ and $3.5 \%$. The dosage was established based on our current experience [25, 26, 29].

The data show that the $35 / 50$ paving grade bitumen exhibited foaming performance typical of harder bitumens with longer half-lives and moderate expansion ratios. The addition of the surfactant had a significant effect on the produced bitumen foam. The half-lives were reduced (especially at low foaming water content $1.5 \%, 2.5 \%$ ) while the expansion ratios increased slightly. The 35/50 binder with the FT synthetic wax alone, as well as that with the simultaneous addition of FT-wax and surfactant resulted in foam quality decrease, compared to the base bitumen. Both half-lives and maximum expansion ratios of the foam decreased, although the effect in the HL $35 / 50+2.5 \% \mathrm{FT}+0.6$ surf. blend was less pronounced. Overall, in the case of the $35 / 50$ bitumen, only the modification with the surfactant was fairly favourable in terms of bitumen foam quality as the half-life at $2.5 \%$ foaming water content did not decrease dramatically, while the expansion ratio increased slightly.

The 50/70 base bitumen showed a moderate foaming potential with comparable expansion ratios and shorter half-lives than those of the $35 / 50$ bitumen at the foaming temperature of $155^{\circ} \mathrm{C}$. The introduction of both modifiers (added alone or in combination) had a similar effect in each case: a decrease in half-lives ( $4 \mathrm{~s}$ on average) and a slight increase in expansion ratios were observed. The mentioned changes were moderate, however, the introduction of the surfactant alone to the $50 / 70 \mathrm{bi}$ tumen may in some cases result in unsatisfactory performance.

Harder binders require more foaming water $(3.5 \% \div 4.0 \%)$ to attain optimal properties of the foam, whereas the 50/70 bitumen with FT wax and surfactant required foaming water content at the level of $2.5 \%$ for optimum foaming performance. a)

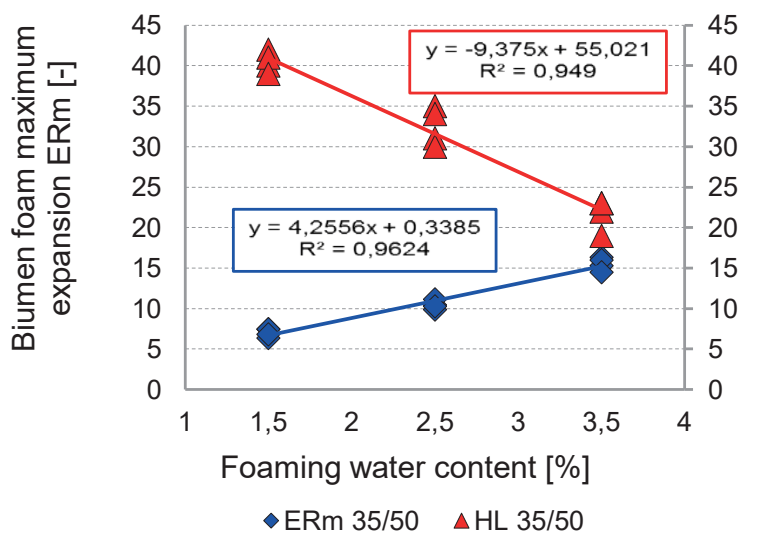

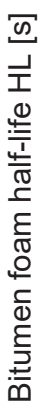

b)

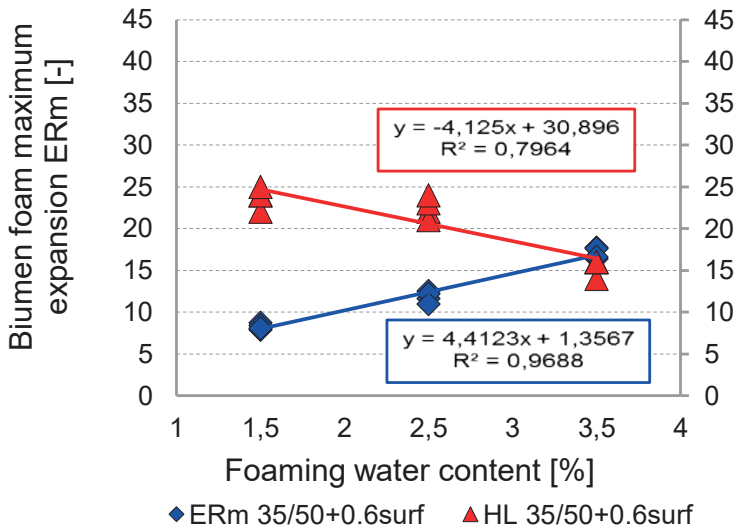

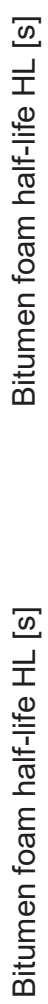

c)

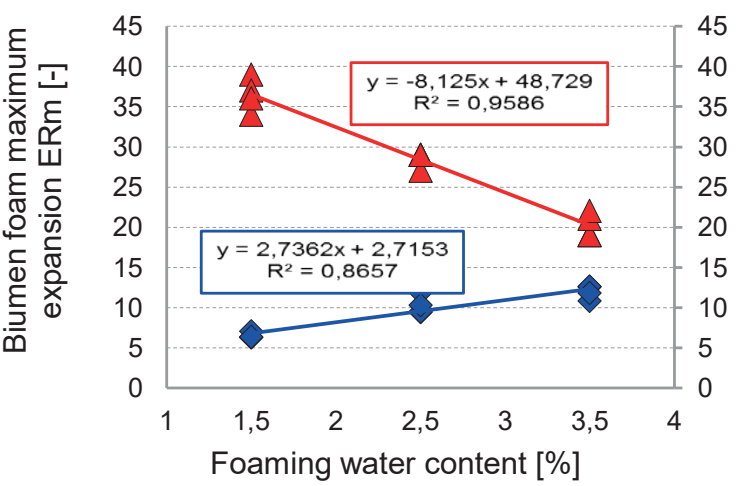

$\diamond \mathrm{ERm} 35 / 50+2.5 \mathrm{FT} \quad \Delta \mathrm{HL} 35 / 50+2.5 \mathrm{FT}$

d)

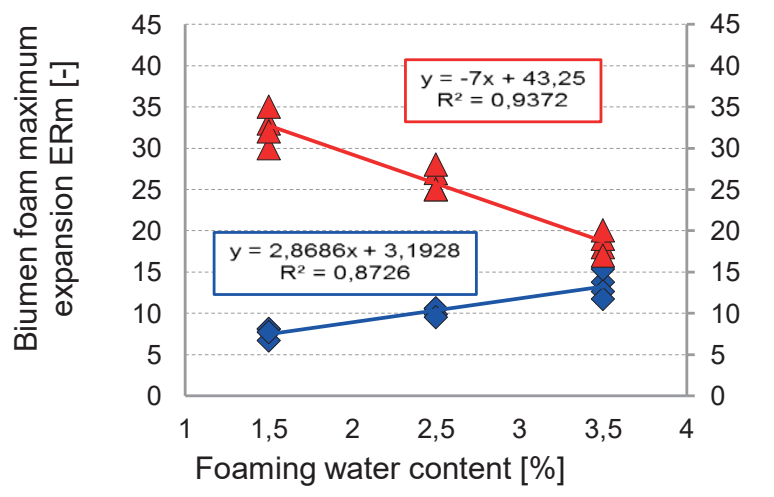

$\diamond \mathrm{ERm} 35 / 50+2.5 \mathrm{FT}+0.6$ surf $\Delta \mathrm{HL} 35 / 50+2.5 \mathrm{FT}+0.6$ surf

Fig 4. Foaming characteristics of 35/50 base and modified binders 
a)

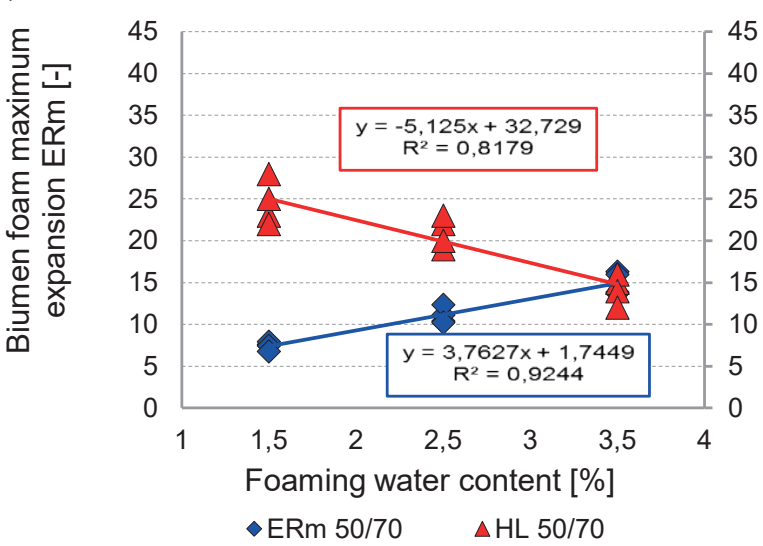

b)

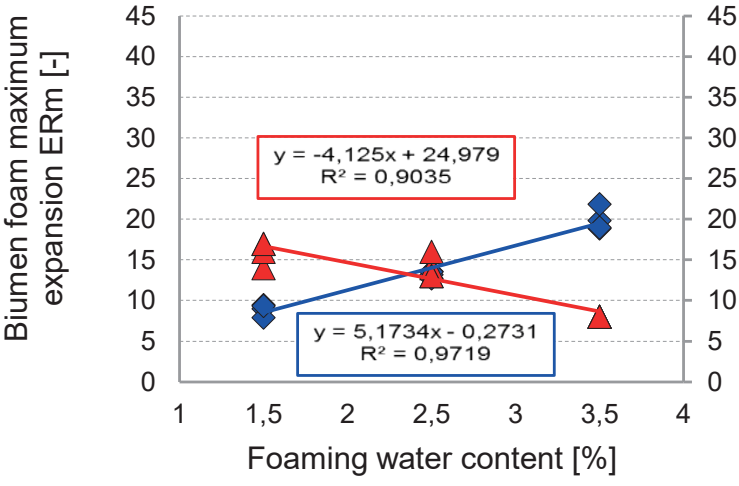

- ERm 50/70+0.6surf $\Delta \mathrm{HL}$ 50/70+0.6surf

c)

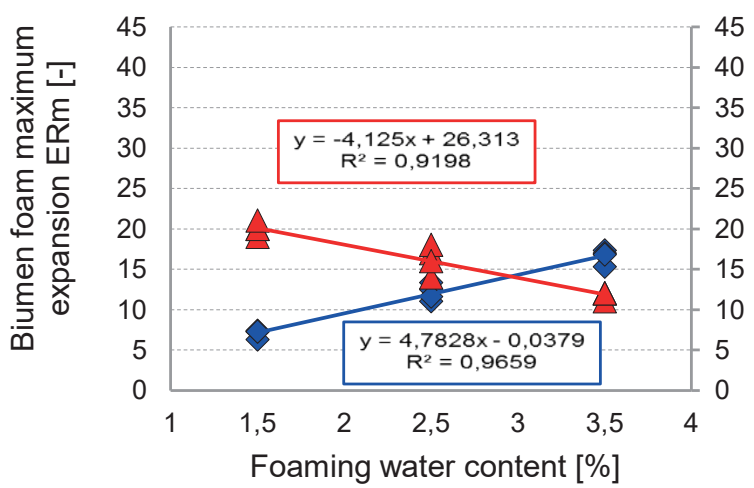

• ERm 50/70+2.5FT $\Delta \mathrm{HL} 50 / 70+2.5 \mathrm{FT}$

d)

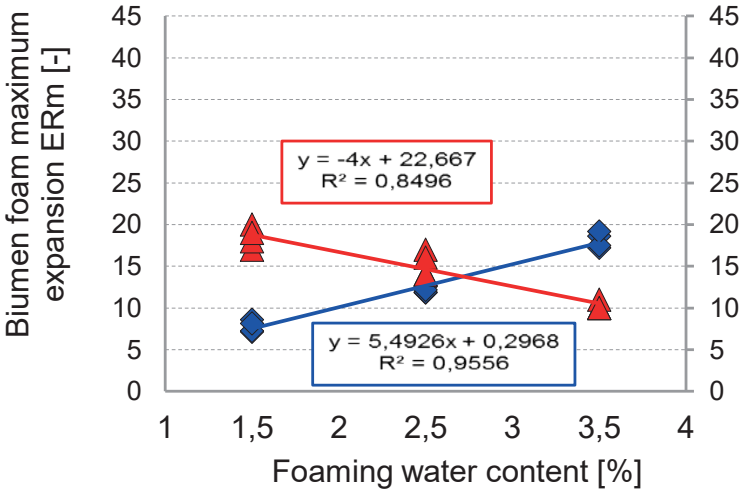

• ERm 50/70+2.5FT+0.6surf $\Delta \mathrm{HL} 50 / 70+2.5 \mathrm{FT}+0.6$ surf

Fig 5. Foaming characteristics of 50/70 base and modified binders
The results of the determination of the optimum content of foaming water (Table 4) indicate that the base bitumens (unmodified) obtained better foaming parameters than modified binders.

Table 4

Foamed bitumen foam properties at optimal foaming water content

\begin{tabular}{|l|c|c|c|}
\hline Binder & ER (-) & HL (s) & $\begin{array}{c}\text { Optimum } \\
\text { FWC (\%) }\end{array}$ \\
\hline $35 / 50$ & 17.4 & 17.5 & 4.0 \\
\hline $35 / 50+0.6 \%$ surf. & 16.8 & 16.5 & 3.5 \\
\hline $35 / 50+2.5 \%$ FT & 16.2 & 13.7 & 4.0 \\
\hline $35 / 50+2.5 \%$ FT +0.6 surf. & 14.7 & 15.3 & 4.0 \\
\hline $50 / 70$ & 14.9 & 14.8 & 3.5 \\
\hline $50 / 70+0.6 \%$ surf. & 12.7 & 14.7 & 2.5 \\
\hline $50 / 70+2.5 \%$ FT & 14.3 & 13.9 & 3.0 \\
\hline $50 / 70+2.5 \%$ FT +0.6 surf. & 14.0 & 12.7 & 2.5 \\
\hline
\end{tabular}

These differences, however, are not large and in terms of the production of asphalt mixes with those additives they can be considered insignificant as the presence of the modifiers has a dominant influence on the properties of asphalt binders both during production and in service of asphalt concrete. The obtained results also indicate the importance of foaming parameters and the high impact of the composition and origin of the binder on its foamability.

\section{$\stackrel{\sigma}{\square} \quad$ 4. Tests for the properties of asphalt concrete for binder courses (AC 16)}

4.1. Materials. The three produced for tests asphalt mixtures were designed to have the most similar possible aggregate mix compositions. The most different was the Mix $C$, where the recycled tyre fibres and FT wax altogether with a surfactant were used.

Table 5 summarizes the materials used to design and to produce asphalt concrete mixes, i.e., mineral aggregates, bituminous binders, modifiers and additives (FT synthetic wax, surfactant, synthetic fibers).

Table 5

Constituents of asphalt mixes AC $16 \mathrm{~W}$

\begin{tabular}{|c|c|c|}
\hline \multirow{2}{*}{$\begin{array}{c}\mathrm{AC} \\
\text { constituents }\end{array}$} & \multicolumn{2}{|c|}{ Mix type and denotation } \\
\hline & Mix-A, Mix-B & Mix-C \\
\hline \multirow[t]{2}{*}{ Aggregate mix } & \multicolumn{2}{|c|}{$\begin{array}{l}\text { Limestone: filler aggregate, } \\
\text { Coarse aggregate } 2 / 8 \mathrm{~mm} \text { and } 8 / 16 \mathrm{~mm} \text {, }\end{array}$} \\
\hline & \multicolumn{2}{|c|}{$\begin{array}{l}\text { Quartzite: fine aggregate } 0 / 2 \mathrm{~mm} \text {, } \\
\text { coarse aggregate } 16 / 22 \mathrm{~mm} .\end{array}$} \\
\hline Adhesion agent & \multicolumn{2}{|c|}{ fatty acid amine surface active agent (surfactant) } \\
\hline $\begin{array}{l}\text { Bituminous } \\
\text { binder }\end{array}$ & $\begin{array}{l}\text { Paving grade } \\
\text { bitumen } 35 / 50\end{array}$ & $\begin{array}{l}\text { Paving grade } \\
\text { bitumen } 50 / 70\end{array}$ \\
\hline $\begin{array}{l}\text { Bitumen } \\
\text { modifiers }\end{array}$ & surfactant & $\begin{array}{l}\text { FT synthetic wax, } \\
\text { surfactant, }\end{array}$ \\
\hline Additives & - & synthetic fibres \\
\hline
\end{tabular}


A. Chomicz-Kowalska

Table 6

Particle size of mineral materials (retained)

\begin{tabular}{|c|c|c|c|c|c|c|c|c|c|c|c|c|c|}
\hline \multirow[t]{2}{*}{ Aggregate } & \multicolumn{13}{|c|}{ Sieve size \# (mm) } \\
\hline & 22.4 & 16 & 11.2 & 8 & 5.6 & 4 & 2 & 1 & 0.5 & 0.25 & 0.125 & 0.063 & $<0.063$ \\
\hline Filler & 0 & 0 & 0 & 0 & 0 & 0 & 0 & 0 & 0 & 0 & 1.3 & 7.7 & 91.0 \\
\hline Fine aggregate $0 / 2 \mathrm{~mm}$ & 0 & 0 & 0 & 0 & 0 & 0 & 4.4 & 29.2 & 35.5 & 18.7 & 8.5 & 2.2 & 1.5 \\
\hline Coarse aggregate $2 / 8 \mathrm{~mm}$ & 0 & 0 & 0 & 2.2 & 27.9 & 45.0 & 21.9 & 1.3 & 0 & 0 & 0 & 0.6 & 1.1 \\
\hline Coarse aggregate $8 / 16 \mathrm{~mm}$ & 0 & 1.8 & 35.0 & 51.1 & 10.5 & 0.5 & 0.3 & 0.1 & 0 & 0 & 0 & 0.2 & 0.5 \\
\hline Coarse aggregate $16 / 22 \mathrm{~mm}$ & 0.5 & 82.5 & 16.5 & 0.2 & 0 & 0 & 0 & 0 & 0 & 0 & 0 & 0.1 & 0.2 \\
\hline
\end{tabular}

4.1.1. Aggregate. Mineral materials that met the requirements of EN 13043:2004, PN-EN 13108-1, TG-1 2010 [30] and TG-2 2010 [18] were used to design the asphalt mix compositions. Table 6 shows the aggregate size distribution for the filler according to PN-EN 933-10 and the remaining mineral materials according to PN-EN 933-1.

4.1.2. Synthetic fibres from recycled tyres. Polymer fibres with a length of less than $30 \mathrm{~mm}$ (Fig. 6), derived from the processing of used car tyres, were incorporated in the low-temperature Mix-C for laboratory testing. This material is recovered

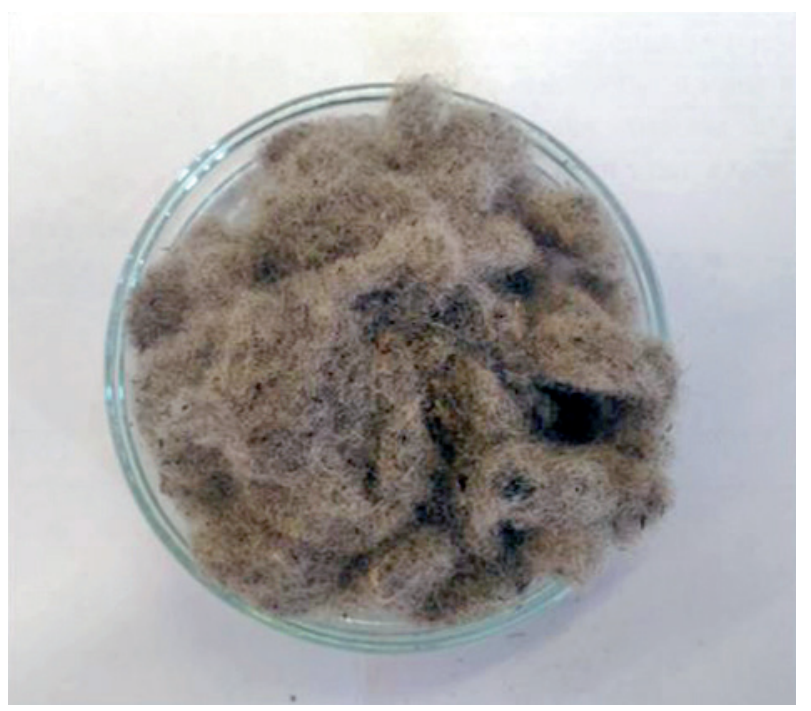

Fig.6. Fibrous material (sybthetic fibers $<30 \mathrm{~mm}$ in length)

through the processing of textile reinforcement in tyres, and is a mixture of synthetic polymer fibres (polyester, viscose, polyamide, para-aramid) and rubber residue. The rubber material has a form of granules with a particle size of less than $8 \mathrm{~mm}$ at the maximum content of $40 \%(\mathrm{~m} / \mathrm{m})$ in the fibres. The crumb rubber had the following grading (relative to the fibrous material) [31]:

- fraction below $0.85 \mathrm{~mm}$ (rubber fines): up to $30 \%$,

- fraction from 0.85 to $2.0 \mathrm{~mm}$ : up to $15 \%$,

- fraction above 2.0 to 8.0 : up to $5 \%$.
Fibres used in asphalt concrete mixtures play a dual role [31]:

- reinforcing the asphalt mix - polymer fibre is a fibre reinforcement improving the resistance to rutting, fatigue cracking and low temperature cracks,

- modifying bituminous binders - rubber fines and crumb rubber contained in the fibrous material alters the properties of the mix and reduces the noisiness of the pavement when applied to the surface layer.

Table 7 shows the basic properties of the fibrous material used in the laboratory tests.

Table 7

Properties of the fibrous additive [31]

\begin{tabular}{|l|c|c|}
\hline Property & Unit & Value \\
\hline Color & - & grey \\
\hline Fiber content & $\%(\mathrm{~m} / \mathrm{m})$ & $70-90$ \\
\hline Crumb rubber content & $\%(\mathrm{~m} / \mathrm{m})$ & $10-30$ \\
\hline Loose (bulk) density & $\mathrm{kg} / \mathrm{m}^{3}$ & $50-80$ \\
\hline Moisture content & $\%$ & $6-8$ \\
\hline Appearance & - & fibers + crumb rubber \\
\hline
\end{tabular}

The presence of high quality, non-biodegradable fibres forming micro-reinforcement in the mix improves pavement resistance to rutting, fatigue and low temperature cracks, water damage, and provides longer fatigue life. Rubber fines and crumb rubber modify bituminous binders, improving their rheological properties [32].

The use of fibrous material does not require additional financial inputs or changes in the process of production, transport and placement of asphalt mixes. Dosing is performed in the same way as in the case of cellulose fibres for stone-mastic-asphalt, i.e., directly into the mineral mix.

In the laboratory tests, $0.2 \%$ of the material containing synthetic fibres and rubber fines (in the proportion of about 80:20) was used, and the principal purpose of their use was to achieve reinforcement effect, which was expected to improve mechanical properties of the asphalt concrete mixture.

4.2. Methodology. In order to determine the impact of the applied technology of AC 16 asphalt concrete mix production (HMA and low temperature asphalt technologies) on the 
changes of its physical and mechanical properties, the following parameters were determined:

- air void content $\mathrm{V}_{\mathrm{m}}$ to PN-EN 12697-8:2005 (9 replicates),

- wet/dry indirect tensile strength ITS $_{\mathrm{d} / \mathrm{w}}$ and moisture susceptibility ITSR to TG-2 2010 [32] and PN-EN 12697-12:2008 (compaction by $2 \times 35$ Marshall blows, $20^{\circ} \mathrm{C}$ vacuum soak $30 \mathrm{~min}, 40^{\circ} \mathrm{C}$ na $72 \mathrm{~h},-18^{\circ} \mathrm{C}$ freeze for $16 \mathrm{~h}, 60^{\circ} \mathrm{C}$ for $24 \mathrm{~h}, 18$ replicates),

- resistance to permanent deformation in wheel tracking test to PN-EN 12697-22:2008 on the basis of rut depth $\mathrm{RD}_{\text {AIR }}$ measurement after 10000 cycles, proportional rut depth $\mathrm{PRD}_{\mathrm{AIR}}$ after 10000 cycles, and wheel tracking slope $\mathrm{WTS}_{\mathrm{AIR}}$ after 10000 cycles (4 replicates),

- stiffness in 4 point bending of a prismatic beam (4PB-PR) to PN-EN 12697-26:2012 (4 replicates),

- resistance to fatigue in 4 point bending of a prismatic beam (4PB-PR) to PN-EN 12697-24:2012(6 replicates).

4.3. Asphalt concrete mix design. In compliance with the Polish requirements [18], in both, the reference mixture of asphalt concrete $(M i x-A)$ and the low temperature foamed bitumen mixture (Mix- $B), 35 / 50$ paving grade bitumen was used. In $M i x-C, 50 / 70$ bitumen was used with $2.5 \%$ synthetic FT wax and $0.6 \%$ surface active substance for improved properties in relation to the remaining AC mixes. The content of hydrophilic aggregate (fine $0 / 2 \mathrm{~mm}$ and coarse $16 / 22 \mathrm{~mm}$ ) in the mineral mix was $40 \%(\mathrm{~m} / \mathrm{m})$. Table 8 gives the frame composition of the mineral and bituminous mixtures.

Table 8

Composition of the asphalt concrete

\begin{tabular}{|l|c|c|c|}
\hline Components & $\begin{array}{c}\text { Mineral mix } \\
(\mathbf{\%} \mathbf{~ m} / \mathbf{m})\end{array}$ & $\begin{array}{c}\text { Mix }-\boldsymbol{A}, \text { Mix }-\boldsymbol{B} \\
(\mathbf{\%} \mathbf{m} / \mathbf{m})\end{array}$ & $\begin{array}{c}\text { Mix }-\boldsymbol{C} \\
(\mathbf{\%} \mathbf{~ m} / \mathbf{m})\end{array}$ \\
\hline Filler - limestone & 5.0 & 4.8 & 4.8 \\
\hline 0/2 mm - quartzite & 32.0 & 30.5 & 30.4 \\
\hline 2/8 mm - limestone & 28.0 & 26.7 & 26.6 \\
\hline 8/16 mm -limestone & 27.0 & 25.8 & 25.8 \\
\hline 16/22 mm - quartzite & 8.0 & 7.6 & 7.6 \\
\hline Road paving bitumen & - & $4.6^{1)}$ & $\left.4.6^{2}\right)$ \\
\hline Recycled sythetic fibers & - & - & 0.2 \\
\hline Suma & 100 & 100 & 100 \\
\hline
\end{tabular}

1) $35 / 50$ bitumen with adhesion agent added at $0.6 \%$ by bitumen mass.

2) $50 / 70$ bitumen modified with $2.5 \%$ FT wax and with adhesion agent in the amount of $0.6 \%$ by bitumen mass.

Gradation of the mineral mix and composition of the asphalt concrete for the binder course were designed according to current technical knowledge. The gradation curve was between the limit points, meeting the requirements of TG-2 2010 Guidelines.

4.4. Manufacture and compaction of asphalt concrete mixtures. The following manufacturing temperature ranges were used during the laboratory tests:
- for the reference asphalt mix (Mix A): production temperature: $\quad 160^{\circ} \mathrm{C} \pm 5^{\circ} \mathrm{C}$, compaction temperature: $\quad 140^{\circ} \mathrm{C} \pm 5^{\circ} \mathrm{C}$,

- for the low temperature asphalt mixes (Mix-B and Mix-C): production temperature: $\quad 130^{\circ} \mathrm{C} \pm 5^{\circ} \mathrm{C}$, compaction temperature: $\quad 120^{\circ} \mathrm{C} \pm 5^{\circ} \mathrm{C}$.

It follows from the technological temperatures above that the foamed bitumen mixtures $(M i x-B, M i x-C)$ had noticeably lower production temperatures (by $30^{\circ} \mathrm{C}$ ) and lower minimum compaction temperatures (by $20^{\circ} \mathrm{C}$ ) compared to the conventional HMA technology $($ Mix- $A)$.

\subsection{Test results and analysis.}

4.5.1. Basic physical and mechanical properties. The measured physical and mechanical values of properties (average values) mentioned in p. 4.2 against the required values as per TG-2 2010 are included in Table 9.

Table 9

Average values of physical and mechanical parameters of AC 16 for binder courses per required values

\begin{tabular}{|l|c|c|c|c|c|}
\hline \multirow{2}{*}{ Property } & \multirow{2}{*}{ Unit } & \multicolumn{3}{|c|}{ Asphalt mix type } & \multirow{2}{*}{$\begin{array}{c}\text { Required } \\
\text { by TG-2 2010 }\end{array}$} \\
\cline { 3 - 5 } & & Mix-A & Mix-B & Mix-C & $4.0 \div 7.0$ \\
\hline $\mathrm{V}_{\mathrm{m}}$ & $\%$ & 5.4 & 6.8 & 4.9 & - \\
\hline $\mathrm{ITS}_{\mathrm{d}}$ & $\mathrm{kPa}$ & 1340.9 & 1326.5 & 1462.2 & - \\
\hline $\mathrm{ITS}_{\mathrm{w}}$ & $\mathrm{kPa}$ & 1115.3 & 1043.4 & 1288.7 & $\geq 80 \%$ \\
\hline ITSR & $\%$ & 83.2 & 78.7 & 88.1 & - \\
\hline $\mathrm{RD}_{\text {AIR }}$ & $\mathrm{mm}$ & 5.35 & 7.22 & 4.52 & - \\
\hline $\mathrm{PRD}_{\text {AIR }}$ & $\%$ & 8.92 & 12,03 & 7.53 & - \\
\hline $\mathrm{WTS}_{\text {AIR }}$ & $\begin{array}{c}\mathrm{mm} / 10^{3} \\
\text { cycles }\end{array}$ & 0.23 & 0.35 & 0,21 & $\leq 0.3$ \\
\hline
\end{tabular}

Analysis of average air void contents in the tested AC mixtures shows the lowest values in the FT wax modified binder with synthetic fibres and surfactant. The low temperature mixture with foamed bitumen from base bitumen 35/50, Mix-B, exhibited the worst compaction $\left(\mathrm{V}_{\mathrm{m}}=6.8 \%\right)$, reaching the upper limit of $7 \%$. Placement of such a mixture may result in a relative reduction in the stability of the entire pavement structure, lower resistance to water and frost damage and greater susceptibility to permanent deformation due to ongoing compaction of the material under vehicle load stresses. Improvement of $\mathrm{V}_{\mathrm{m}}$ by approximately $10 \%$ in $M i x-C$ relative to the reference mix $M i x-A$ is a result of the blend of the synthetic wax and surfactant incorporated into the foamed binder. The effect of Fischer-Tropsch wax and liquid surface active agent in Mix-C resulted in contributed to coating of mineral material and better workability and compaction of the mix at lower temperatures. It is difficult to judge unequivocally the effect of synthetic fibre addition on asphalt mix compaction, but it did not affect low air void content. A lower air void content (better compaction) reults in a higher resistance to unfavourable climatic conditions (water and low temperatures). In summary, all the designed blends met the $\mathrm{V}_{\mathrm{m}}$ specification, which according to TG-2 2010 must be between $4 \%$ and $7 \%$. 
Analysis of the ITSR values indicates that they were influenced by the technology of asphalt mix production (HMA, WMA), mix compositions and the type of bituminous binder applied to them. Mix-C had the highest values of indirect strength of all the mixes under analysis, both under air-dry conditions and after conditioning with one freezing cycle. The decrease in indirect tensile strength due to water conditioning with a freezing cycle for mixes A and C was less than $20 \%$, which means that these mixes have met the TG-2 2010 requirements in this respect (ITSR $\geq 80 \%$ ). In the case of Mix- $B$, which exhibited the lowest indirect tensile strengths, the impact of water and frost was the greatest, as represented by low ITSR $=78.7 \%$ that failed to meet the requirements. The presence of Fischer-Tropsch wax in bitumen $50 / 70$ as well as synthetic fibres in the asphalt concrete mix resulted in the expected effects of improving ITSR values and increasing the indirect tensile strength. Compared to the reference Mix-A (HMA), the values of ITS $_{\mathrm{d}}$ and $\mathrm{ITS}_{\mathrm{w}}$ in Mix-C were higher by about $8 \%$ and $12 \%$, respectively. The indirect tensile strength drop was smaller in Mix- $C$ for water-conditioned samples, resulting in ITSR of $88.1 \%$, which was about $5 \%$ higher than that for the reference mix. It follows from the above that the results of indirect tensile strength measurements and calculated ITSRs are consistent with the relationship observed while determining the air void content in the samples, i.e., mixtures with higher $V_{m}$ values exhibited worse water and frost resistance (in particular, Mix-B).

The resistance to permanent deformation of $\mathrm{AC} 16$ mixes was affected by the production technology used (hot and low temperatures) and their composition or binder type. As for the requirements for mixes intended for the KR3-KR4 TG-2 2010 pavement binder course, only Mix- $B$ failed to meet the requirement for $\mathrm{WTS}_{\mathrm{AIR}}$, which should not exceed $0.3 \mathrm{~mm} / 10,000$ cycles. Analysis of the results obtained for $\mathrm{WTS}_{\mathrm{AIR}}$ and $\mathrm{PRD}_{\mathrm{AIR}}$ shows the worst-case (highest) values in $M i x-B$, produced at lower temperatures, based on conventional 50/70 foamed bitumen (with no FT modifier and surfactant), with the highest susceptibility for rutting of all mixes. The mixture produced at lower temperatures, containing FT-modified bitumen and recycled scrap-tyre fibres showed the most favourable mechanical characteristics, i.e., the lowest wheel tracking slope and proportional rut depth with respect to Mix-A produced in HMA technology. The presence of the modifier, additive and fibrous material in bitumen 50/70 was definitely beneficial for the mechanical properties of Mix-C. Synthetic wax stiffened the binder structure at service temperatures and raised the softening temperature thus reducing the rutting sensitivity of the AC $16 \mathrm{~W}$ mix. In addition, the presence of synthetic fibres acting as reinforcement strengthened the structure of the mix. A similar effect was observed during the assessment of indirect tensile strengths. Favourable mechanical characteristics obtained for Mix-C will result in increased durability of the pavement, thus improving the safety of road users.

4.5.2. Stiffness and fatigue resistance. An important step in the study was to assess the performance of the designed asphalt concrete mixtures intended for the binder course in terms of the complex stiffness modulus and fatigue resistance. The tests were performed on prismatic beams cut out from compacted slabs. The beams were subjected to four-point bending by applying a cyclic sinusoidal load by forcing the target strain (beam deflection). All the tests were performed at $10^{\circ} \mathrm{C}$. The AC stiffness was tested on 4 specimens, while the fatigue resistance was determined on 6 beams from each mix. First, the values of complex stiffness moduli were determined. As asphalt mixtures are viscoelastic materials, their behaviour depends not only on test temperature but also on the frequency (speed) of loading. Figure 7 shows the dependencies of the complex stiffness moduli of the mixes on loading frequency $(1 \mathrm{~Hz}, 3 \mathrm{~Hz}, 5 \mathrm{~Hz}, 10 \mathrm{~Hz}, 30 \mathrm{~Hz})$.

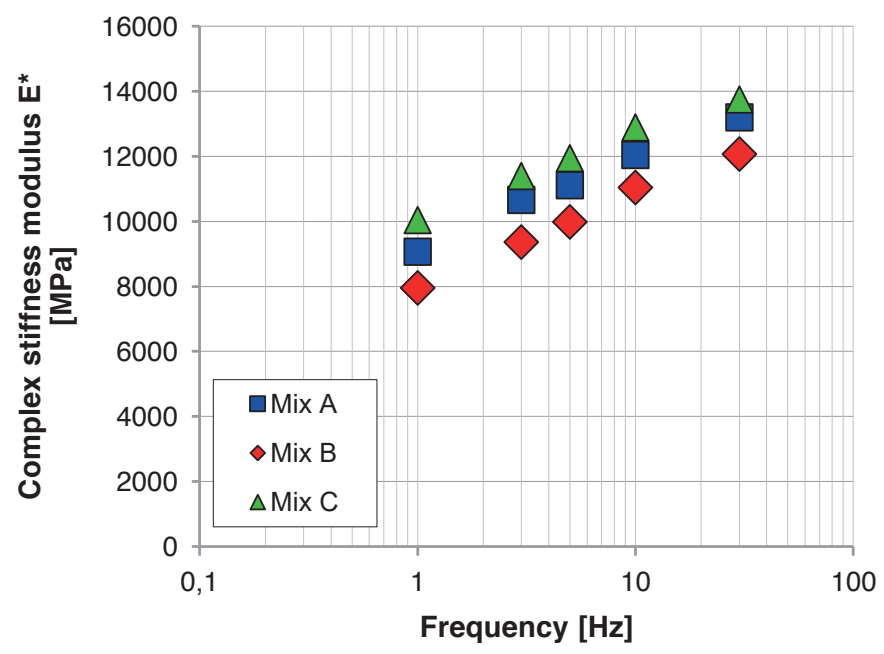

\begin{tabular}{cccc}
\hline \multirow{2}{*}{ Frequency $[\mathrm{Hz}]$} & \multicolumn{3}{c}{ E* $^{*}$ std. dev. } \\
\cline { 2 - 4 } & Mix-A & Mix-B & Mix-C \\
\hline 1 & 348.17 & 300.88 & 442.54 \\
3 & 395.60 & 348.48 & 494.32 \\
5 & 591.37 & 568.91 & 549.70 \\
10 & 795.04 & 571.18 & 845.45 \\
30 & 742.12 & 804.19 & 895.32 \\
\hline
\end{tabular}

Fig 7. Complex stiffness moduli of Mix-A, Mix-B, Mix-C determined in $4 \mathrm{~PB}-\mathrm{PR}$ at $10^{\circ} \mathrm{C}$ and in the frequency range of $1 \mathrm{~Hz} \div 30 \mathrm{~Hz}$

The obtained results indicate a significantly higher stiffness of Mix-C observed over a wide range of loading frequencies. In addition, the behaviour of the stiffness in the frequency domain may indicate a lower sensitivity of Mix-C with respect to Mix- $A$ for temperature variations and/or loading frequency. The stiffness results classify all the mixes in the same category $\mathrm{S}_{\min 11000}$ as their stiffness exceeds $11,000 \mathrm{MPa}$. At the same time, it is important to note that the stiffness moduli of Mix-C and $M i x-A$ are similar and both substantially higher than that of $M i x-B$.

Figure 8 shows the results of the fatigue life tests, determined at the given strain level equal to $115 \cdot 10^{-6}$.

The classical fatigue criterion assumes that the fatigue life of asphalt mixes reaches its limit when the stiffness modulus decreases to less than $50 \%$ of its initial value (determined between 45 and 100 test cycles). According to this criterion, all of the tested mixtures have fatigue life of more than 1 million 


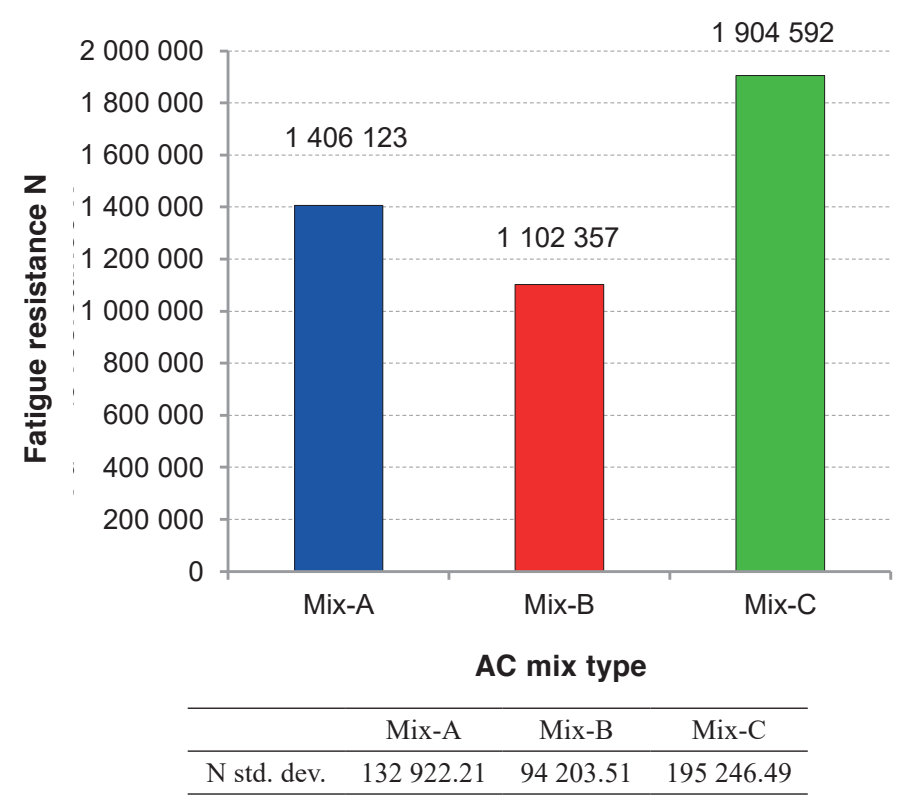

Fig. 8. Fatigue life of mixes A, B and $\mathrm{C}$ determined in $4 \mathrm{~PB}-\mathrm{PR}$ at $10^{\circ} \mathrm{C}$ and at loading frequency of $10 \mathrm{~Hz}(115 \mu \varepsilon$ amplitude)

load cycles at the applied strain of $115 \mu \varepsilon$ (microstrains). Thus both mixtures can be classified in fatigue resistance category $\varepsilon_{6-115}$ required for most asphalt mixtures. Although the tested mixes are classified in one fatigue resistance category, Mix- $C$ has fatigue life approximately $30 \%$ longer from that of Mix- $A$ at this level of strains, which will directly increase durability and service life of the pavement with the binder course made of foamed bitumen mix containing a FT wax modified binder, a surface active substance addition, and synthetic fibers from recycled car tyres.

\section{Conclusions}

The following conclusions were formulated on the basis of $\mathrm{AC}$ 16 tests:

- Simultaneous use of synthetic FT wax at 2.5\% and the surfactant at $0.6 \%$ provided foaming characteristics of bitumen $50 / 70$ (expansion ratio and half-life) comparable to the neat bitumen and made it possible to manufacture and compact the asphalt mix at substantially lower temperatures relative to the energy-intensive HMA technology;

- The inferior performance of the low temperature Mix-B with foamed $35 / 50$ bitumen was mainly caused by the high amount of air void content in the mix; the foaming of $35 / 50$ bitumen alone provided insufficient compaction aid for a mix with $35 / 50$ bitumen compacted at $120^{\circ} \mathrm{C}$;

- The foamed bitumen with both additives provided the mix intended for the binder course $(M i x-C)$ with a higher resistance to permanent deformation, compared to the reference HMA mix $(M i x-A)$;

- The use of fibrous material recovered from waste tyres in the asphalt mix $($ Mix $-C)$ had a positive effect on the perfor- mance of the mix in terms of resistance to climatic factors (water and low temperatures) and traffic load (resistance to rutting);

- Mix-C was significantly stiffer than the reference mix, Mix- $A$, which can provide a final pavement with prolonged service life;

- The tests for fatigue life revealed an improved resistance of Mix $-C$ to fatigue, owing to which degradation of the pavement with the binder course made with the AC 16 mix, FT wax-modified 50/70 binder and the addition of surfactant and fibrous fibres will be deferred and the service life of such pavement will be longer.

The use of synthetic fibres recovered from used car tyres as a fibre reinforcement brings environmental benefits through the disposal of this waste, while extending the durability of the surface and reducing the demand for natural materials. Under conditions of increasing loading of the pavement, the use of synthetic fibres from recycled car tires in asphalt mixtures is favourable as it can improve the durability and service life of the road pavement structure. Compared with the conventional HMA technology, the low temperature asphalt mix production technology using foamed bitumen meets the requirements and trends concerning reduced $\mathrm{CO}_{2}$ emissions and energy efficiency.

Acknowledgements. The scientific investigations, results of which are presented in this work, were conducted within a project titled. "The use of recycled materials" under "RID" co-funded by the National Centre for Research and Development and the General Directorate for National Roads and Motorways in Poland.

\section{REFERENCES}

[1] J. Komacka, E. Remisova, G. Liu, G. Leegwater, and E. Nielsen: "Influence of reclaimed asphalt with polymer modified bitumen on properties of different asphalts for a wearing course," Sustainability, Eco-efficiency, and Conservation in Transportation Infrastructure Asset Management [Proc. ICTI], 179-185 (2014), doi: 10.1201/b16730-27.

[2] A. Chomicz-Kowalska, M.M. Iwański, and J. Mrugała, "Basic performance of fiber reinforced asphalt concrete with reclaimed asphalt pavement produced in low temperatures with foamed bitumen," IOP Conf. Ser.: Mater. Sci. Eng., vol. 245, 1-9 (2017).

[3] M. Wasilewska, W. Gardziejczyk, A. Plewa, and P. Gierasimiuk, "Use of reclaimed asphalt pavement to asphalt concrete base course," Rocznik Ochrony Środowiska, 17 (2), 973-997 (2015).

[4] M. Iwański and A. Chomicz-Kowalska, "Evaluation of the pavement performance", Bull. Pol. Ac.: Tech. 63 (1), 97-105 (2015), doi:10.1515/bpasts-2015-0011.

[5] A. Woszuk, A. Zofka, L. Bandura, and W. Franus: "Effect of zeolite properties on asphalt foaming," Construction and Building Materials, vol 139, 247-255 (2017), doi: 10.1016/j. conbuildmat.2017.02.054.

[6] A. Chomicz-Kowalska, W. Gardziejczyk, and M.M Iwański, "Moisture resistance and comactibility of asphalt concrete produced in half-warm mix asphalt technology with foamed bitumen," Construction and Building Materials, vol. 126, 108-118 (2016), doi:10.1016/j.conbuildmat.2016.09.004. 
[7] M.F.C Van De Ven, K.J. Jenkins, J.L.M. Voskuilen, and R. Van Den Beemt: "Development of (half-) warm foamed bitumen mixes: State of the art," International Journal of Pavement Engineering, vol. 8(2), 163-175 (2007), doi: 10.1080/10298430601149635.

[8] A. Vaitkus, D. Cygas, A. Laurinavicius, V. Vorobjovas, and Z. Perveneckas, "Influence of warm mix asphalt technology on asphalt physical and mechanical properties," Construction and Building Materials, vol. 112, 800-806 (2016), doi:10.1016/j.conbuildmat.2016.02.212.

[9] B. Dołżycki, M. Jaczewski, and C. Szydłowski, "The Influence of Binding Agents on Stiffness of Mineral-cement-emulsion Mixtures," Procedia Engineering, Modern Building Materials, Structures and Techniques, vol. 172, 239-246 (2017), doi:10.1016/j.proeng.2017.02.103.

[10] J. Król, K. Kowalski, and P. Radziszewski, "Rheological behavior of n-alkane modified bitumen in aspect of Warm Mix Asphalt technology," Construction and Building Materials, vol. 93, 703-710 (2015), doi:10.1016/j.conbuildmat.2015.06.033.

[11] M. Iwański, P. Buczyński, and G. Mazurek, "The use of gabbro dust in the cold recycling of asphalt paving mixes with foamed bitumen," Bull. Pol. Ac.: Tech. 64(4), 763-773 (2016), doi:10.1515-0085.

[12] J. Čorej, M. Korenko, and E. Remišová, "Climatic characteristics and the temperature regime of asphalt pavements," Komunikacie, vol. 6(3), 31-36 (2004).

[13] M. Kadela, "Model of multiple-layer pavement structure-subsoil system," Bull. Pol. Ac.: Tech. 64 (4), 173-181 (2016), doi: 10.1515/bpasts-2016-0084.

[14] P. Mackiewicz, "Fatigue Tests of Bituminous Mixtures with Inclusion of Initial Cracks", Journal of Materials in Civil Engineering, Vol. 25 (1), (2013), doi.org/10.1061/(ASCE)MT.1943-5533.0000581.

[15] A.C. Pronk, M. Gajewski, and W. Bańkowski, "Application of a material fatigue damage model in 4PB tests", International Journal of Pavement Engineering, 2016, doi.org/10.1080/10298436.2016.1210441

[16] B. Goszczyńska, G. Świt, and W. Trąmpczyński, "Monitoring of active destructive processes as a diagnostic tool for the structure technical state evaluation", Bull. Pol. Ac.: Tech. 61(1), 97-108 (2013), doi:10.2478/bpasts-2013-0008.

[17] L. Czarnecki and P. Woyciechowski, "Prediction of the reinforced concrete structure durability under the risk of carb onation and chloride aggression", Bull. Pol. Ac.: Tech. 61 (1), 173-181 (2013), doi: 10.2478/bpasts-2013-0016.

[18] TG-2 2010. Nawierzchnie asfaltowe na drogach krajowych. Mieszanki mineralno-asfaltowe [Asphalt pavements on government road. Bituminous mixtures]. Wymagania Techniczne [Technical Guide]. GDDKiA, Warszawa.
[19] P. Radziszewski, K. Kowalski, J. Król, M. Sarnowski, and J. Piłat, "Quality assessment of bituminous binders based on the viscoelastic properties: polish experience," Journal of Civil Engineering and Management, vol. 1(20), 111-120 (2014), doi: 10.3846/13923730.2013.843586.

[20] A. Chomicz-Kowalska, J. Mrugała, and K. Maciejewski, "Evaluation of foaming performance of bitumens modified with the addition of surface active agent," IOP Conf. Ser.: Mater. Sci. Eng., vol. 245, 1-10 (2017).

[21] E. Remisova, "Theory and measurements of bitumen binders adhesion to aggregate," Komunikacie, vol. 6(1), 58-63 (2004).

[22] M. Carmen Rubio, G. Martinez, L. Baena, and F. Moreno, "Warm mix asphalt: an overvie" Journal of Cleaner Production, vol. 24, 76-84 (2012), doi:10.1016/j.jclepro.2011.11.053

[23] H Silva, J. Oliveri, J. Peralta, and S. Zoorob, "Optimization of warm mix asphalt using different blends of binders and synthetic paraffin wax contents," Construction and Building Materials, 24(9), 1621-1631 (2010), doi:10.1016/j.conbuildmat.2010.02.030.

[24] M. Iwański and G. Mazurek, "Optimization of the synthetic wax content on example of bitumen 35/50," 11th International Conference on Modern Building Materials, Structure and Techniques, Vilnius, Lithuania, Elsevier, Procedia Engineering, Vol. 57, 414-423 (2013), doi. 10.1016/j.proeng.2013.04.054

[25] M. Iwański, A. Chomicz-Kowalska, and K. Maciejewski, "Application of synthetic wax for improvement of foamed bitumen parameters," Construction and Building Materials, vol. 83, 62-69 (2015), doi: 10.1016/j.conbuildmat.2015.02.060.

[26] A. Chomicz-Kowalska, "Statistical methods for evaluating associations between selected foamed bitumen parameters," In: Proceedings of the 6th International Conference on Bituminous Mixtures and Pavements - ICONFBMP 2015. CRC Press/ Balkema, 3-12 (2015).

[27] www.minova.pl

[28] I. Gaweł, M. Kalabińska, and J. Piłat, 2001. Asfalty drogowe [Road bitumen], WKŁ, Warszawa, Poland, 255 p.

[29] M. Iwański, A. Chomicz-Kowalska, and J. Mrugała, "Application of the synthetic wax to improve the foamed bitumen parameters used in half-warm bituminous mixtures," International Conference on Environmental Engineering (ICEE), 154, 1-9 (2014).

[30] TG-1 2010. Kruszywa do mieszanek mineralno-asfaltowych i powierzchniowych utrwaleń na drogach krajowych [Aggregates for mineral-bitumen mixes on national roads and highways]. Wymagania Techniczne [Technical Guide]. GDDKiA, Warszawa.

[31] Aprobata Techniczna IBDiM, Nr AT/2006-03-1991. Nazwa wyrobu: Włóknisty materiał stabilizująco-wzmacniająco-modyfikujący TOFIC do mieszanek mineralno-asfaltowych.

[32] D. Sybilski, A. Wróbel, and W. Bańkowski, Nowe włókno TOFIC® do poprawy właściwości mieszanek mineralno-asfaltowych. IBDiM. 